\title{
Using the Sales Process as an Instructional Tool to Improve Student Perceptions of Instructor Responsiveness, Pedagogical Affect, and Likelihood to Enroll: An Abstract
}

\author{
Cindy Rippé, Shannon Cummins, Suri Weisfeld-Spolter, and Yuliya Yurova
}

\begin{abstract}
This research explores the communication-centered commonalities of selling and teaching. A conceptual model positing professor used selling activities of prospecting and follow-up positively impact student perceptions of instructor responsiveness, pedagogical affect, and likelihood to enroll is empirically tested. Modality type, professor communication style, and timing of appeal are shown to have moderating effects, indicating that selling activities can be beneficial across course formats, before or during a class, and virtually or in person. Using a scenario methodology with a sample of 274 online and ground students, results show promise for educators using selling activities as a communication tool in any subject.
\end{abstract}

References Available Upon Request

\footnotetext{
C. Rippé $(\bowtie)$

Tarleton State University, Stephenville, TX, USA

e-mail: rippe@ tarleton.edu

S. Cummins

University of Wisconsin-Whitewater, Whitewater, WI, USA

e-mail: cumminss@uww.edu

S. Weisfeld-Spolter $\bullet$ Y. Yurova

Nova Southeastern University, Fort Lauderdale, FL, USA

e-mail: sw887@nova.edu; yy21@nova.edu
} 